\title{
SKRINING DAN UJI ANTAGONISME JAMUR TRICHODERMA HARZIANUM YANG MAMPU BERTAHAN DI FILOSFER TANAMAN JAGUNG
}

\author{
Efri, Joko Prasetyo1, dan Radix Suharjoı
}

\begin{abstract}
Screening and antagonism test of Trichoderma harzianum which are survived on the corn phyllosphere. The research was conducted to find Trichoderma harzianum that could survive on the corn phyllosphere which still have good antagonism capability. Five isolates T. harzianum were used in the research. Spore suspension of each isolate T. harzianum (108 spore/ $\mathrm{ml}$ ) was sprayed to the 21 days after planting corn phyllosphere in the afternoon. Reisolation in order to obtain the isolates which were was conducted in $1-22$ days after spraying. To the extend that 3 isolates (from $T$. sprayed before harzianum) that could survive on the corn filosfeer and have the best antagonism capability then collected. Antagonism test was carried out using dual culture method. Phytophthora capsici was used as the antagonism object. The result showed that T. harzianum could survive until 22 days after spraying (DAS) on the last leaves (isolate 1,2,3 and 5). On the second leaves, T. harzianum could survive 17 DAS Isolate 4 and 5), and 20 DAS (isolate 5) on the meristem leaves. Antagonism test showed isolate 1 from reisolated from the last leaves $\left(\mathrm{ThRI}_{1}\right)$, isolate 4 reisolated from the second leaves $\left(\mathrm{ThDI}_{4}\right)$ dan isolate 5 reisolated from meristem leaves ( $\mathrm{ThTI}_{5}$ ) were 3 isolates that have the best antagonism capability.
\end{abstract}

Key words : Trichoderma harzianum, corn phyllosphere

\section{LATAR BELAKANG}

Penyakit bulai yang disebabkan oleh Peronosclerospora maydis merupakan penyakit penting dan merupakan salah satu faktor pembatas peningkatan kualitas dan kuantitas produksi jagung, khususnya di Indonesia (Iriany et al., 2003; Budiarti et al., 2002; Azrai et al., 2003). Setiap tahun, luas serangan penyakit bulai ini terus meningkat. Pada tahun 2004, di Indonesia luas serangan mencapai 4837 ha, 563 ha diantaranya mengalami puso. Di Propinsi Lampung, pada tahun 2004 luas serangan mencapai 2504 ha, dengan 548 ha diantaranya mengalami puso atau gagal panen (Anonim, 2006).

Pengendalian penyakit bulai pada umumnya dilakukan dengan cara menanam varietas tahan atau dengan perlakuan benih dengan menggunakan fungisida sintetis (Iriany et al., 2003; Semangun, 2004). Jenis fungisida sintetis yang saat ini banyak digunakan untuk perlakuan benih adalah metalaksil. Hampir semua benih jagung yang beredar di pasaran diperlakukan dengan metalaksil. Akan tetapi masih sering terjadi ledakan serangan penyakit bulai di berbagai daerah sentra produksi jagung, tidak terkecuali di Lampung. Diduga, ledakan bulai ini salah satunya disebabkan oleh munculnya $P$. maydis strain tahan terhadap metalaksil. Bains \& Dhaliwal (1994) melaporkan bahwa dalam jangka panjang, penggunaan metalaksil dapat menyebabkan munculnya jamur patogen yang tahan terhadap metalaksil. Selain itu, penggunaan metalaksil juga akan mengakibatkan matinya mikroorganisme yang menguntungkan dalam tanah (Menge, 1982).

Uraian di atas membuktikan bahwa saat ini sangat perlu untuk mencari alternatif pengendalian terhadap penyakit bulai yang lebih efektif dan ramah lingkungan. Salah satu strategi yang saat ini sedang diteliti dan dikembangkan adalah penggunaan agensia hayati, diantaranya adalah Trichoderma spp. Jamur Trichoderma spp. telah banyak dilaporkan sebagai antagonis yang efektif untuk pengendalian patogen tumbuhan pada berbagai patosistem (Vasudevan et al., 2002; Ownley, 2002). Namun begitu, sampai saat ini belum ada laporan tentang penggunaan agensia hayati khususnya jamur Trichoderma spp. untuk menekan penyakit bulai pada jagung. Oleh karena itu dianggap perlu untuk melakukan penelitian tentang kemampuan

\footnotetext{
1 Jurusan Proteksi Tanaman, Fakultas Pertanian, Universitas Lampung,

Jl. Prof. Sumantri Brodjonegoro No. 1 Bandar Lampung 35145. Email : efri@unila.ac.id
} 
Trichoderma spp. untuk menghambat perkembangan $P$. maydis. Karena $P$. maydis merupakan patogen yang bersifat air borne (tular udara) yang berasosiasi pada daerah filosfer (permukaan daun) maka jamur antagonis yang akan diaplikasilan harus mampu beradaptasi di daerah filosfer. Oleh karena itu dianggap perlu untuk melakukan penelitian tentang kemampuan Trichoderma spp. yang mampu beradaptasi di filosfer untuk menghambat perkembangan $P$. maydis.

\section{METODE PENELITIAN}

Penelitian ini dilaksanakan di Laboratorium Penyakit Tumbuhan, Fakultas Pertanian, Universitas Lampung, pada bulan Maret - November 2008. Metode yang digunakan dalam penelitian ini mengacu pada metode yang dikembangkan oleh Prasetyo \& Aeny (2006) yang telah dimodifikasi dengan langkah-langkah sebagai berikut :

Perbanyakan jamur T. harzianum. Sebanyak 5 isolat (isolat Th1, Th2, Th3, Th4 dan Th5) jamur hasil penelitian Prasetyo \& Aeny (2006) ditumbuhkan dan diperbanyak di dalam cawan petri berisi media Potato Dextrose Agar (PDA) yang telah diberi antibiotik Pimaricin 0,1 ppm. Spora jamur ini kemudian disemprotkan ke daun jagung untuk dicari isolat yang mampu bertahan hidup di daun jagung tersebut.

Persiapan tanaman jagung sebagai inang. Tanaman jagung yang digunakan merupakan tanaman jagung yang berumur 21 hari setelah tanam. Tanaman jagung ditanam di dalam polibag berukuran $5 \mathrm{~kg}$ dengan media tanam berupa tanah dan pupuk kandang dengan perbandingan $1: 1$.

Inokulasi ke daun tanaman jagung. Sebanyak $0,5 \mathrm{~kg}$ gula (sukrosa) dilarutkan ke dalam 1 liter suspensi spora jamur $T$. harzianum dengan kerapatan $10_{8}$ spora/ml. Penambahan gula pada suspensi bertujuan sebagai sumber makanan awal bagi jamur T. harzianum di filosfer tanaman jagung. Suspensi T. harzianum yang mengandung gula tersebut masing-masing disemprotkan secara merata permukaan daun tanaman jagung pada sore hari.

\section{Re-isolasi jamur T. harzianum dari daun tanaman} jagung. Re-isolasi dilakukan setiap hari sampai dengan 22 hari setelah inokulasi pada tiga bagian tanaman jagung (titik tumbuh, daun ke-2 dan daun terakhir). Re- isolasi dilakukan dengan cara daun jagung diambil, dipotong kecil-kecil berukuran $1 \mathrm{~cm}_{2}$ dan ditumbuhkan dalam cawan petri berisi media Potato Dextrose Agar mengandung antibiotik Pimaricin sebanyak 0,1 ppm.

Pengamatan dan pengumpulan data. Pengamatan dilakukan pada isolat jamur Trichoderma harzianum yang mampu bertahan hidup pada daun tanaman jagung pada 1 sampai dengan 22 hari setelah inokulasi.

Pengamatan terhadap jamur T. harzianum. Koloni T. harzianum yang tumbuh dari hasil re-isolasi dapat diketahui dengan warna koloni hijau tua dan dilakukan pengamatan terhadap struktur mikro yang mencirikan jamur $T$. harzianum tersebut di bawah mikroskop. Isolat jamur $T$. harzianum yang tumbuh kemudian dimurnikan dan ditumbuhkan ke dalam $P D A$ miring yang berisi antibiotik Pimaricin 0,1 ppm. Setelah tumbuh, kemudian dipreservasi dengan minyak parafin cair steril dan disimpan di dalam almari es untuk pengujian lanjutan.

Uji kepastian isolat hasil re-isolasi. Pengujian ini dilakukan untuk memastikan bahwa isolat yang ditemukan merupakan isolat yang telah diaplikasikan sebelumnya. Langkah re-identifikasi dilakukan dengan cara melakukan re-isolasi daun tanaman jagung yang hanya diaplikasikan dengan air steril tanpa diaplikasikan dengan $T$. harzianum yang dilakukan selama 5 hari berturut-turut. Langkah-langkah reisolasi yang dilakukan sama dengan langkah re-isolasi pada daun tanaman jagung yang telah diaplikasikan dengan $T$. harzianum. Apabila dari hasil re-isolasi nantinya tidak ditemukan T. harzianum maka dapat dipastikan bahwa isolat hasil re-isolasi tersebut merupakan isolat yang telah diaplikasikan sebelumnya.

\section{Pemilihan 3 isolat terbaik jamur T. harzianum.}

Isolat yang terbaik adalah isolat yang dapat bertahan hidup lama di filosfer daun jagung tanpa mempengaruhi kemampuan antagonisnya. Peronosclerospora maydis adalah parasit obligat sehingga tidak dapat dilakukan uji antagonis dengan Trichoderma terpilih secara in vitro. Oleh karena itu pemilihan isolat selanjutnya dilakukan dengan cara melakukan uji antagonisme isolat terpilih dengan jamur Phytophthora capsici yang dibandingkan dengan kemampuan antagonisnya sebelum diaplikasikan di filosfer. Pemilihan jamur $P$. capsici karena jamur tersebut masih termasuk dalam satu ordo dengan jamur Peronosclerospora maydis, penyebab penyakit bulai (Peronosporales) (Alexopoulos et al., 1996). Dengan 
kekerabatan yang masih dekat ini, maka diharapkan nantinya akan memberikan hasil penghambatan yang tidak jauh berbeda terhadap $P$. maydis.

Uji antagonisme dilakukan pada media Potato Dextrose Agar (PDA) dalam cawan petri. Bagian bawah cawan petri diberi tanda garis tengah dengan spidol marker. Sebuah titik dengan jarak $3 \mathrm{~cm}$ dari tepi cawan petri kemudian ditentukan sebagai tempat meletakkan inokulum $P$. capsici yang berupa potongan bor gabus, sedangkan dari tepi yang lain juga diukur dengan jarak yang sama sebagai tempat meletakkan potongan bor gabus biakan Trichoderma harzianum (Gambar 1). Kemudian diinkubasikan selama 3-4 hari.

\section{HASIL DAN PEMBAHASAN}

Kemampuan jamur Trichoderma harzianum untuk bertahan hidup di daerah filosfer tanaman jagung. Hasil pengamatan menunjukkan bahwa jamur T. harzianum yang disemprotkan ke tiga bagian tanaman jagung (titik tumbuh, daun ke-2 dan daun terakhir) mulai tumbuh bervariasi dari hari ke-3 hingga hari ke-5 setelah re-isolasi. Koloni jamur T. harzianum hasil re-isolasi menunjukkan warna awal putih dan selanjutnya akan berubah menjadi hijau tua, bentuk percabangan konidiofor membentuk piramid dan konidia berbentuk bulat berdinding halus.

Hal ini menunjukkan bahwa jamur yang direisolasi tersebut merupakan jamur T. harzianum yang telah diinokulasikan sebelumnya. Hal ini diperkuat dengan hasil reisolasi dari daun tanaman jagung yang tidak diaplikasikan dengan T. harzianum. Dari hasil reisolasi yang dilakukan 5 hari berturut-turut tersebut ternyata tidak ditemukan $T$. harzianum.
Hasil reisolasi memperlihatkan bahwa kelima isolat yang disemprotkan ke tiga bagian daun tanaman jagung menunjukkan kemampuan bertahan hidup yang berbeda-beda. Beberapa isolat ada yang bertahan sampai dengan 22 hari setelah inokulasi dan ada beberapa isolat yang dapat bertahan hanya 17 hari setelah aplikasi penyemprotan (Tabel 1).

Tabel 1 menunjukkan bahwa $T$. harzianum mampu bertahan hidup sampai 22 hari pada bagian daun terakhir tanaman jagung. Pada bagian daun ke-2, T. harzianum mampu bertahan selama 17 hari, sedangkan pada bagian titik tumbuh, jamur $T$. harzianum mampu bertahan selama 20 hari.

Pada bagian titik tumbuh tidak secara langsung terkena sinar matahari. Bagian titik tumbuh akan terlindung oleh daun-daun yang ada di sekelilingnya. Hal ini menyebabkan sinar ultraviolet yang sampai ke daerah tersebut akan cenderung sedikit. Selain itu, kondisi ini akan menyebabkan daerah tersebut mempunyai tingkat kelembaban yang lebih tinggi. Hal ini juga terjadi pada daerah daun terakhir. Daerah daun terakhir akan terlindungi oleh daun-daun yang ada di atasnya. Kondisi ini memberi kesempatan bagi $T$. harzianum untuk dapat bertahan lebih lama.

Hal ini berbeda dengan kondisi bagian daun ke2. Pada bagian daun ke-2, sinar matahari secara langsung mengenai permukaan daun. Kenyataan ini menyebabkan sinar ultraviolet yang sampai ke daerah tersebut akan cenderung besar. Selain itu, kondisi ini menyebabkan daerah tersebut mempunyai tingkat kelembaban yang lebih rendah. Tekanan lingkungan ini menyebabkan kesempatan bagi T. harzianum untuk dapat bertahan di daerah tersebut akan cenderung lebih kecil.

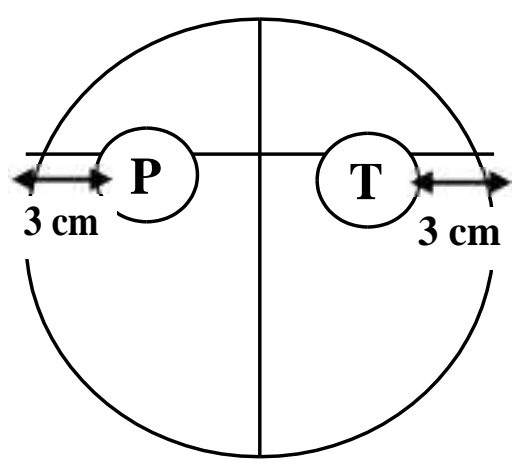

Gambar 1. Cara peletakan inokulum P. capsici dan Trichoderma harzianum.

Keterangan : $\mathbf{P}=$ Biakan $P$. capsici, $\mathbf{T}=$ Biakan Trichoderma harzianum. 


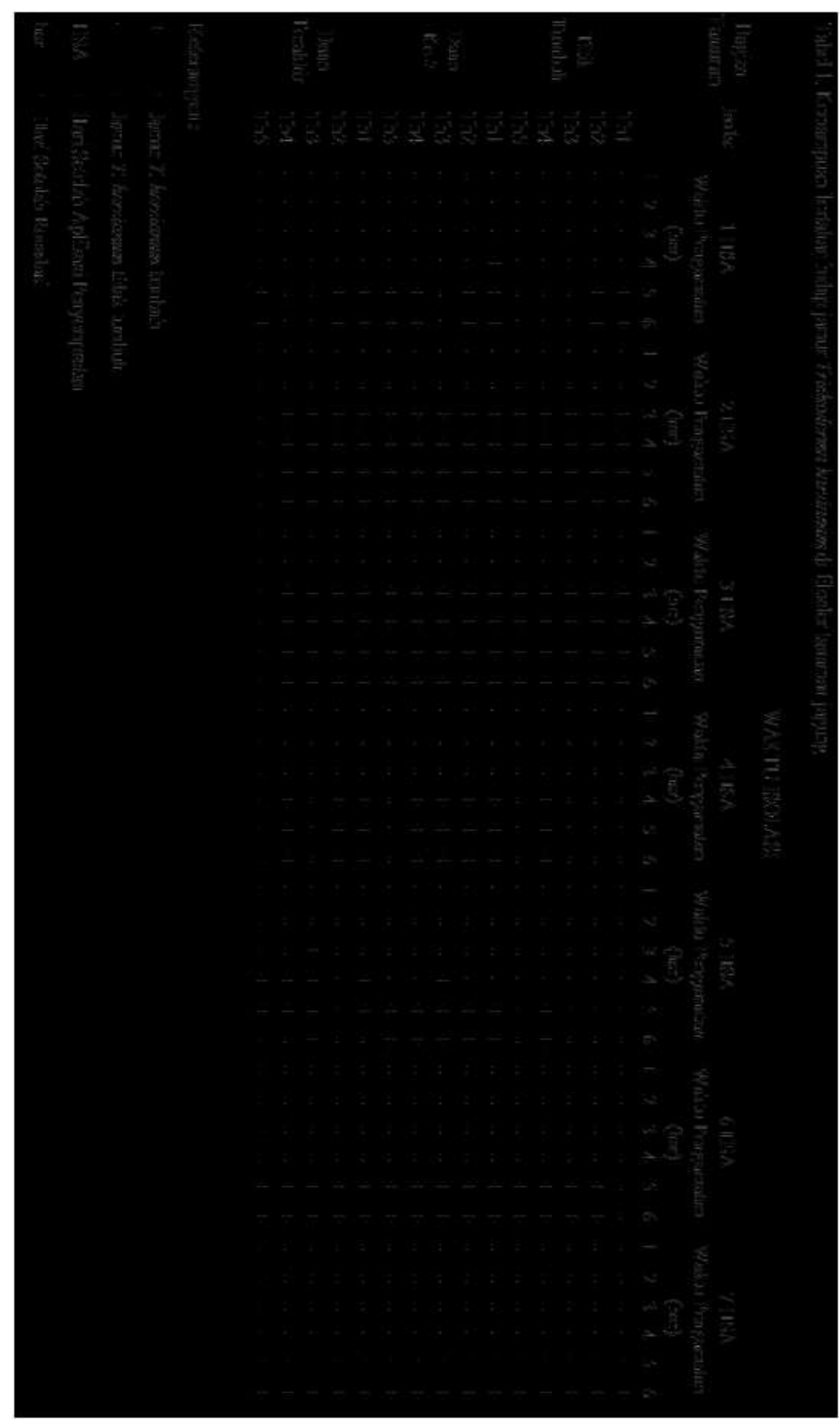




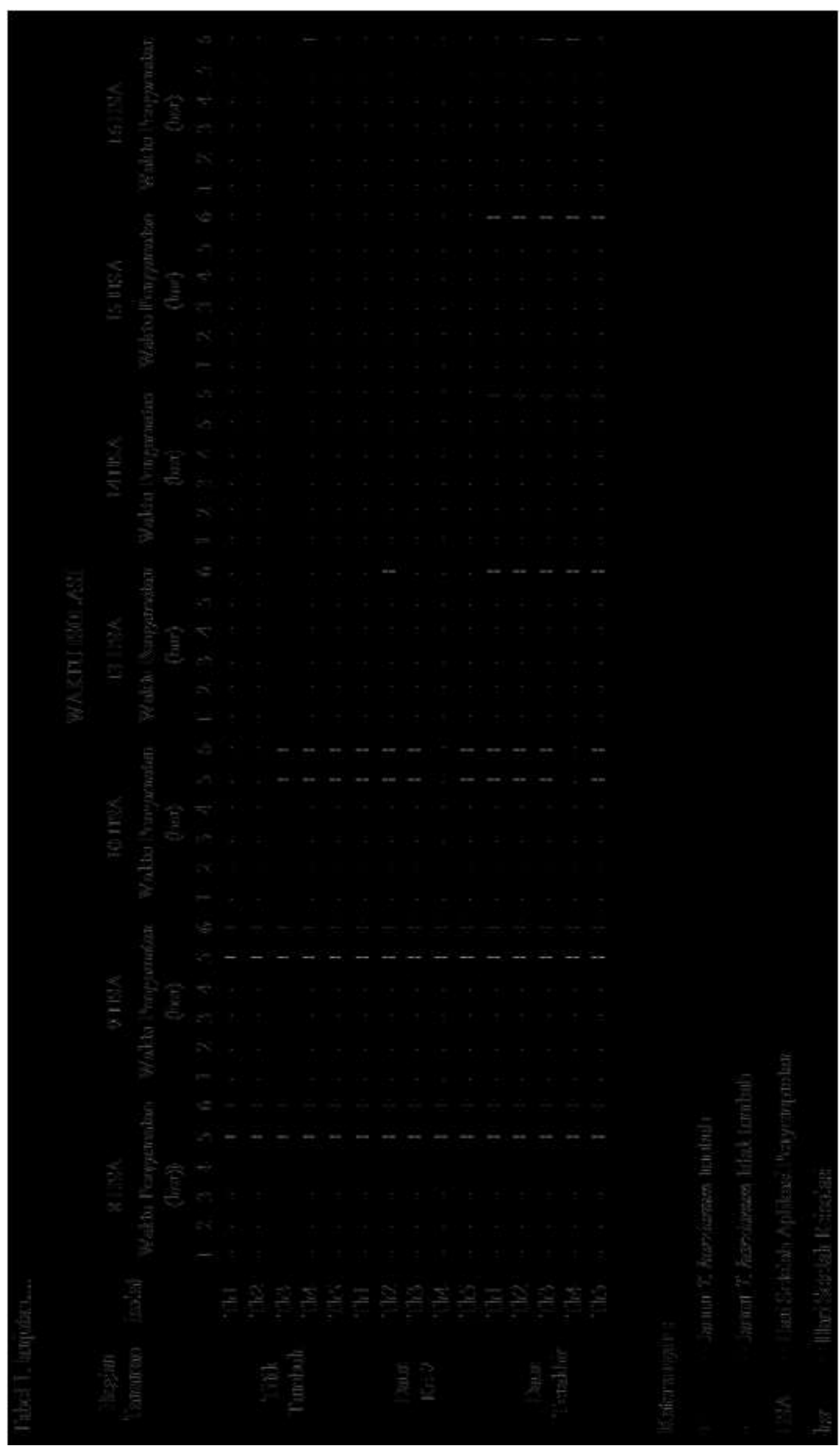




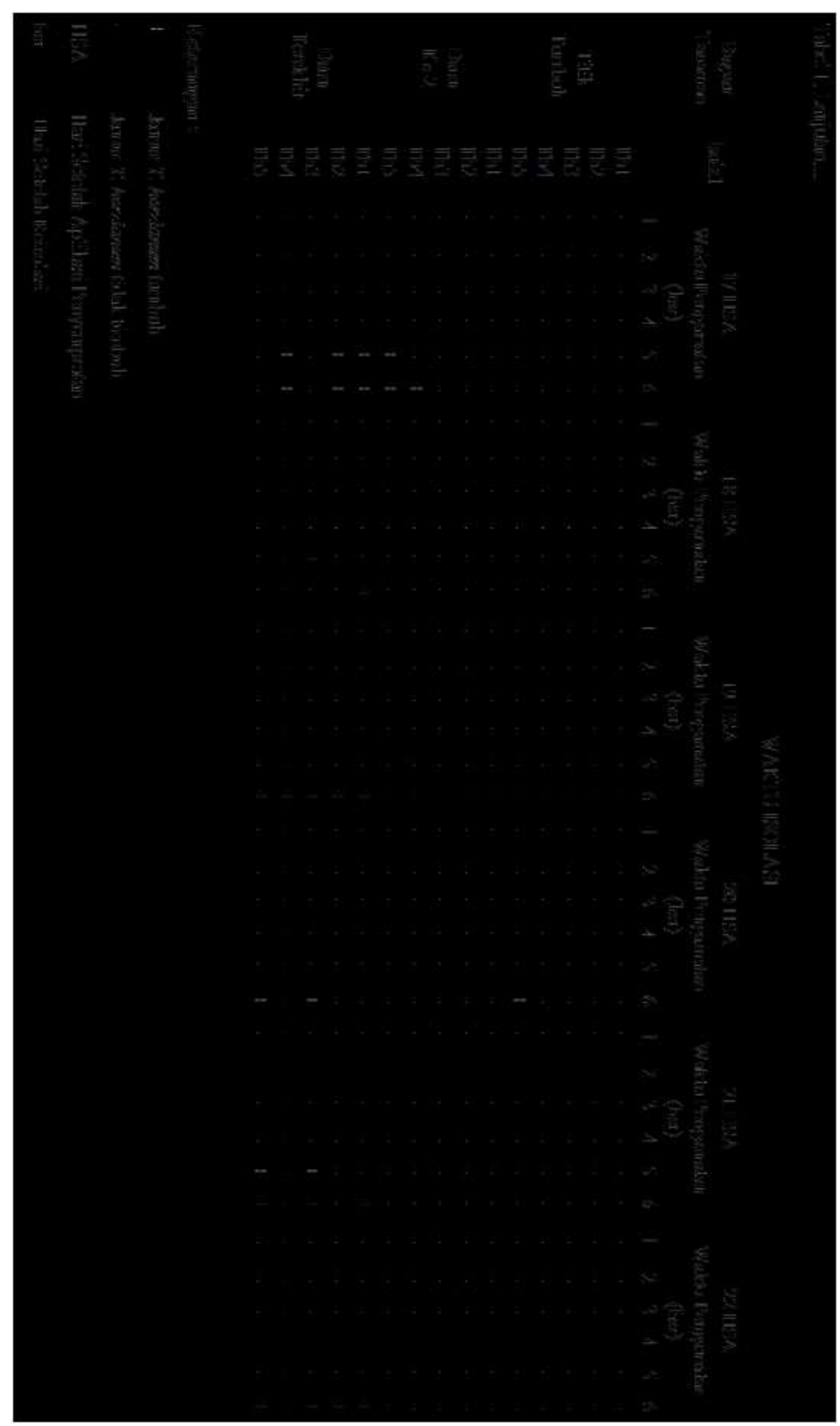


Tabel 2. Isolat-isolat jamur T. harzianum yang mampu bertahan paling lama pada tiga bagian daun tanaman jagung

\begin{tabular}{|c|c|c|}
\hline Bagian tanaman & Lama bertahan & Isolat \\
\hline Titik tumbuh & $\begin{array}{c}20 \text { hari setelah aplikasi } \\
\text { penyemprotan }\end{array}$ & Th5 \\
\hline Daun ke-2 & $\begin{array}{l}17 \text { hari setelah aplikasi } \\
\text { penyemprotan }\end{array}$ & Th4 dan Th5 \\
\hline Daun terakhir & $\begin{array}{l}22 \text { hari setelah aplikasi } \\
\text { penyemprotan }\end{array}$ & Th1, Th2, Th3 dan Th5 \\
\hline
\end{tabular}

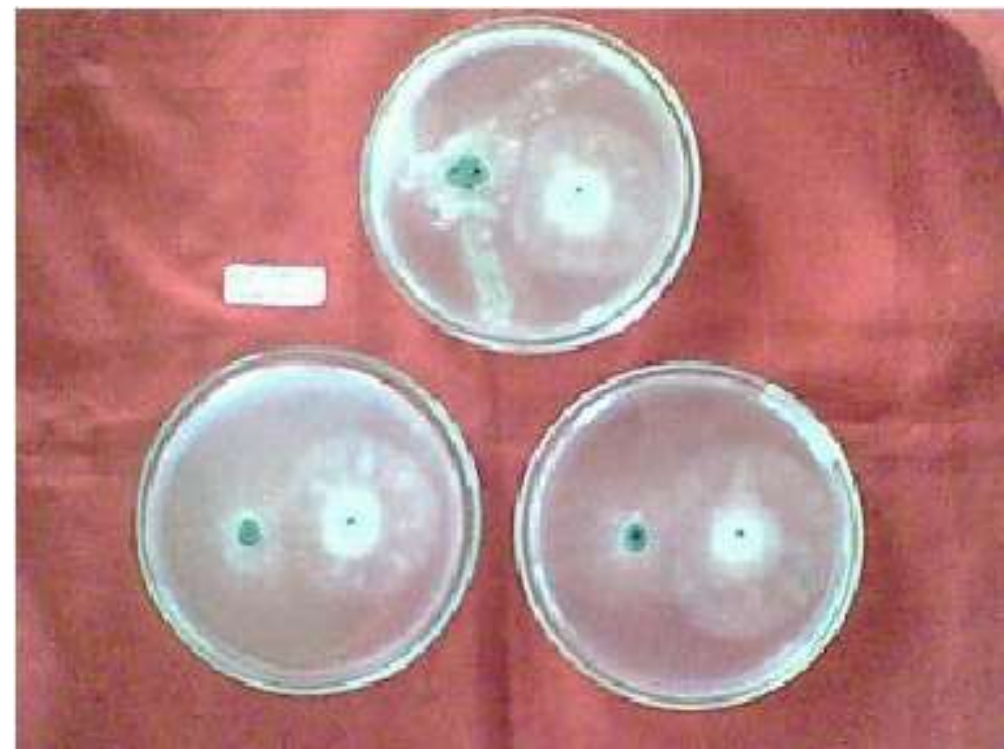

Gambar 4. Uji Antagonisme T. harzianum hasil reisolasi dengan Phytophthora capsici

Isolat jamur T. harzianum terpilih. Isolat jamur

T. harzianum terpilih merupakan isolat jamur

T. harzianum yang mampu bertahan hidup paling lama daun tanaman jagung dan mempunyai kemampuan antagonisme yang baik. Dari hasil screening pada bagian titik tumbuh didapatkan isolat 5 yang dapat bertahan pada 20 hari setelah aplikasi penyemprotan, pada bagian daun ke- 2 didapatkan isolat 4 dan 5 yang dapat bertahan pada 17 hari setelah aplikasi penyemprotan dan pada daun terakhir didapatkan isolat 1, 2, 3 dan 5 yang dapat bertahan pada 22 hari setelah aplikasi penyemprotan (Tabel 2).

Tabel 2 menunjukkan bahwa terdapat lebih dari satu isolat yang dapat tumbuh di bagian daun tanaman jagung (pada daun ke-2 dan daun terakhir). Pemilihan isolat selanjutnya dilakukan dengan cara melakukan uji antagonisme isolat yang ditemukan dengan jamur Phytophthora capsici.
Hasil pengujian menunjukkan bahwa isolat Th1 daun terakhir $\left(\mathrm{ThRI}_{1}\right)$, isolat Th4 daun kedua $\left(\mathrm{ThDI}_{4}\right)$ dan isolat Th5 titik tumbuh ( $\mathrm{ThTI}_{5}$ ) merupakan 3 isolat yang memiliki persentase penghambatan terbaik. Dengan begitu, ketiga isolat tersebut merupakan tiga isolat terpilih. Hasil uji statistik menunjukkan bahwa isolat T. harzianum yang didapatkan dari hasil reisolasi memiliki kemampuan penghambatan yang bervariasi bila dibandingkan dengan $T$. harzianum yang tidak diaplikasikan ke tanaman jagung (sebagai kontrol) (Tabel $3)$.

Tabel 3 menunjukkan bahwa isolat Th1, Th2, Th3 dan Th4 hasil reisolasi dari daun tanaman jagung baik dari titik tumbuh, daun kedua serta daun terakhir dan isolat Th1, Th2, Th3, Th4 yang tidak diaplikasikan ke tanaman jagung menunjukkan hasil yang tidak berbeda nyata. Hasil yang sama juga ditunjukkan oleh isolat Th5 hasil reisolasi dari daun terakhir, sedangkan isolat 5 hasil 
Tabel 3. Persentase penghambatan $T$. harzianum terhadap $P$. capsici pada 4 hari setelah inokulasi

\begin{tabular}{cc}
\hline Isolat & Persentase penghambatan (\%) \\
\hline ThT.I & 90,00 ab \\
ThD.I. & 90,00 ab \\
ThD.I $I_{5}$ & 65,56 def \\
ThR.I. $_{1}$ & 94,44 a \\
ThR.I $_{2}$ & 61,11 ef \\
ThR.I & 81,11 abcd \\
ThR.I & 52,22 f \\
I $_{1}$ & 96,67 a \\
I $_{2}$ & 88,89 ab \\
$\mathrm{I}_{3}$ & 83,33 abc \\
$\mathrm{I}_{4}$ & 74,45 bcde \\
$\mathrm{I}_{5}$ & 68,91 cdef \\
\hline
\end{tabular}

Angka dalam satu kolom yang ikuti dengan huruf yang sama menunjukkan hasil yang tidak berbeda nyata pada uji BNT 5\%

Keterangan :

ThT.I I , ThT.I5 masing-masing ialah T. harzianum isolat 4 dan 5 hasil reisolasi dari titik tumbuh ThD.I ${ }_{4}$, ThD.I I masing-masing ialah $T$. harzianum isolat 4 dan 5 hasil reisolasi dari daun ke 2

ThR.I I ,ThR.I I $_{2}$, ThR.I $I_{3}$, ThR.Is masing-masing ialah T. harzianum isolat 1, 2, 3, 5 hasil reisolasi dari daun terakhir

$\mathrm{I}_{1}, \mathrm{I}_{2}, \mathrm{I}_{3}, \mathrm{I}_{4}, \mathrm{I}_{5}$ masing-masing ialah isolat $T$. harzianum isolat 1, 2, 3, 4 yang belum diaplikasikan ke tanaman jagung sebagai kontrol

reisolasi dari titik tumbuh menunjukkan hasil yang secara nyata lebih baik. Kenyataan ini menunjukkan bahwa daerah titik tumbuh tanaman jagung lebih sesuai bagi perkembangan $T$. harzianum.

Hasil uji statistik tersebut menunjukkan bahwa kemampuan antagonis isolat-isolat T. harzianum hasil reisolasi tidak mengalami perubahan bahkan menjadi lebih baik setelah diaplikasikan ke tanaman jagung.

\section{SIMPULAN}

Dari hasil penelitian dapat disimpulkan bahwa :

1. Jamur Trichoderma harzianum mampu bertahan di filosfer tanaman jagung. T. harzianum mampu bertahan selama 17 hari setelah aplikasi ke tanaman jagung (HSA) hingga 22 HSA.

2. Isolat-isolat $T$. harzianum yang diaplikasikan pada tanaman jagung masih memiliki kemampuan antagonisme yang baik.

3. Tiga isolat $T$. harzianum yang mampu bertahan hidup selama 17 sampai 22 hari di filosfer tanaman jagung dengan kemampuan antagonisme terbaik berturutturut adalah ThR.I1, ThT.Is, dan ThD.I4.

\section{DAFTAR PUSTAKA}

Alexopoulos, C.J. \& C.W. Wims. 1996. Introductory Mycologi. John Willey and Sons, New York.

Anonim. 2006. Data Luas Serangan Organisme Pengganggu Tumbuhan: Data OPT Penting Tanaman Jagung. Direktorat Jenderal Tanaman Pangan. Departemen Pertanian RI. <http:// www.deptan.go.id/ditlin-tp/BASISDATA/ D ATA_ OP T / IN DE X _ D ATA_OP T. ht ml . Diakses tanggal 24 Maret 2007>.

Azrai, M. \& F. Kasim. 2003. Analisis Varians dan Heritabilitas Ketahanan Galur Jagung Rekombinan terhadap Penyakit Bulai. Penelitian Pertanian Tanaman Pangan 22(1) : 31 - 35 . $<$ http://www.pempropsu.go.id/download.php? filename $=$ Analisis $\% 20$ Varians.pdfdanid=KA-01. Diakses tanggal 26 Maret 2007>. 
Bains, S.S. \& H.S. Dhaliwal. 1994. Downy Mildews of Maize. Pages: 212-234, in U.S. Singh, U.N.

Mukhopadhyay, J. Kumar, \& H.S. Chaube (eds.). Plant Diseases of International Imprtance. Vol 1: Disease of Cereals and Pulses. Prentice Hall, Englewood Cliffs, NJ.

Budiarti, S.G., Sutoro, Hadiatmi, \& H. Purwanti. 2002. Pembentukan dan Evaluasi Inbrida Jagung Tahan Penyakit Bulai. Prosiding Seminar Hasil Penelitian Rintisan dan Bioteknologi Tanaman hlm 193 - $198<\mathrm{http}: / /$ www.indobiogen.or.id/ terbitan/prosiding/fulltext_pdf/ prosiding2002_193-98_srigajatri.pdf. Diakses tanggal 24 Maret 2007>.

Iriany, M., R. N. A. Takdir, M. Muzdalifah, M. M. Dahlan, \& Subandi. 2003. Evaluasi Daya Gabung Karakter Ketahanan Tanaman Jagung terhadap Penyakit Bulai Melalui Persilangan Diallel. Penelitian Tanaman Pangan 22 (3).http:// www.pempropsu.go.id/download.php? filename=Daya\%20Gabung.pdfdanid=KA-01. Diakses tanggal 24 Maret 2007.
Menge, J.A. 1982. Effect of fumigans and fungicides on vesicular arbuscular fungi. Phytophatology $72: 1125-1132$.

Ownley, B.H. 2002. Biological Control of Tobacco Diseases. Pages: 111-130, in S.S. Gnanamanickam (ed.). Biological Control of Crop Diseases. Marcel Dekker, New York.

Prasetyo, J. \& T.N. Aeny. 2006. Diversity and Abundance of Soil-borne Pathogenic Fungi in Various Land-use System in Sumberjaya, Lampung. Jurnal Hama dan Penyakit Tumbuhan Tropika 6 (2) : 107 - 112.

Semangun, H. 2004. Penyakit-penyakit Tanaman Pangan Di Indonesia. Gadjah Mada University Press. Yogyakarta.

Vasudevan, P., S. Kavitha, V.B. Priyadarisini, L. Babujee, \& S.S. Gnanamanickam. 2002. Biological Control of Rice Diseases. Pages: 1163, in S.S. Gnanamanickam (ed.). Biological Control of Crop Diseases. Marcel Dekker, New York. 